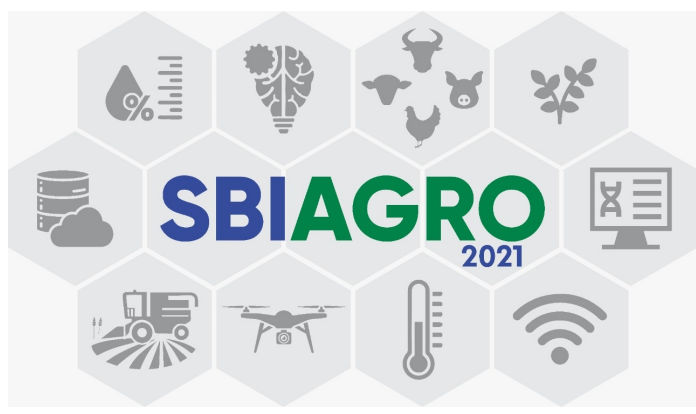

\section{Towards an IoT-Based Architecture for Monitoring and Automated Decision-Making in an Aviary Environment}

\author{
Vinícius C. Lopes ${ }^{1}$, Roberto Felício de Oliveira ${ }^{2}$, \\ Valdemar Vicente Graciano Neto ${ }^{1}$
}

GoIn-Sight: Goiás Information Systems and Software Engineering Research Team Instituto de Informática (INF) - Universidade Federal de Goiás (UFG)

Caixa Postal 131 - CEP 74001-970 - Goiânia - GO - Brazil

${ }^{2}$ Universidade Estadual de Goiás (UEG) - UnU-Posse

CEP 73900-000 - Posse - GO - Brazil

vinilopes03@discente.ufg.br, roberto.oliveira@ueg.br, valdemarneto@ufg.br

\begin{abstract}
Internet of Things (IoT) is a prominent technology in which everyday objects can be equipped with identifying, sensing, networking, and processing capabilities that allow them to communicate with each another and with other devices and services over the Internet to achieve some goal. In agribusiness, the use of technologies, such as IoT, is called precision livestock farming, which includes the use of different technologies in production and care of livestock animals. Brazil is one of the largest poultry producers in the world, being the first in exportation. Despite that, poultry production faces difficulties due to sensitivity that birds have to numerous environmental factors in aviaries, such as lightning, sounds, harmful gases, air humidity, food quality and clean water. When these variables are not well controlled, problems in meat quality and poultry production are likely to occur. As a result, farmers may face severe financial losses. Thus, providing a healthy environment is essential, and to achieve this, accurate monitoring and fast decision making are required in order to solve the problem as soon as possible. In this paper a detailed process of requirements elicitation and architectural design for IoT-Based aviary monitoring systems is proposed along with an informal literature review from the area. As preliminary results, we delivered a requirements document with functional and nonfunctional requirements closer to the real needs of farmers and an architectural proposal that can be used as a reference for further studies.
\end{abstract}




\section{Introduction}

Brazil is one of the largest poultry producers in the world, being the first in exportation, according to the Brazilian Association of Animal Protein (ABPA) [Pessoa et al. 2013]. Nevertheless, domestic poultry production often faces difficulties due to the sensitivity that birds have to numerous factors of ambience in the aviary. The temperature is one of the factors that most impacts on losses of aviculture production [da Silva Oliveira et al. 2019], which can be due, for instance, to the imbalance of the birds' thermal comfort zone. The imbalance of the environment is not only caused by the temperature. There are other variables that influence the welfare of poultry, such as lightening, harmful gases, air humidity, food quality and clean water [Mumbelli et al. 2020].

Providing a healthy environment requires a monitoring and control practices, such as decision-making [Mumbelli et al. 2020]. A human must decide when and how to solve aviary's problems, such as the need to warm up or cool down the environment, also controlling the process of renewing aviary's air and the supply of water and feed, without having any waste [Choukidar and Dawande 2017]. However, a human by himself cannot execute these tasks with precision needed, since a person is subject to fatigue and physiological needs, such as sleeping, preventing 24/7 monitoring, which can expose the birds to temperature variations and other factors that can be fatal [Camargo et al. 2019]. Therefore, the need for a system that could automate and assist in this process is evident.

Developing a system that successfully addresses the major needs of the agribusiness is far from trivial. Despite huge difficulty, it is something that needs to be achieved, since the loss of production would have a huge impact on producers and in the poultry's market, mainly on the financial issue. For example, in Brazil, chicken consumption in 2020 was around 45 kilos of chicken meat/per capita, which is an increase of $5 \%$ compared to 2019 (42.84 kilos). For that reason, poultry production must keep up with the increase in consumption and failures must not happen during the monitoring activity, otherwise, it would negatively impact the country's economy. So, systems and technologies developed for this area must achieve a high level of quality and reliability, since it can be classified as critical systems. Thus, a well-structured and defined architecture is needed.

Thus, the main contribution of our study so far is providing preliminary results of an exploratory study on software architecture for monitoring an environment of an aviary and to support and automate the decision-making. Our general goal is to propose an architectural design that solve the problems faced in the daily basis of real farmers, specifically: (i) the need for a faster and more accurate decision-making in poultry management, (ii) the need to monitor the environment 24 hours a day, (iii) the stress level of the poultry inside the aviary. All of these problems can be related to critical systems due to potential losses, and those losses may strongly affect producers financially.

The remainder of this paper is structured as follows: Section 2 presents the background, Section 3 the methodology adopted by this study, Section 4 the results obtained so far with this study and Section 5 the final considerations of this paper.

\section{Background}

In agribusiness sector, which includes rural producers, farmers and ranchers, some terms are relevant, such as Precision livestock farming. This term refers to the application 
of technology in the production and care of livestock animals. The aim of this technology is to manage animals by continuous real time health monitoring, welfare, production/reproduction, and environmental impact [Berckmans 2006]. The monitoring activity can be done by sensors, cameras connected to the internet and the aid software application it can assist the farmer's decision-making. Another synonymous term with precision livestock farming also used in this study is livestock 4.0. However, for conceiving any engineering system, requirements elicitation is an essential activity.

In software engineering, software requirements refer to the needs and constraints placed on a software product that contribute to the solution of some realworld problem [Bourque and Fairley 2014]. Requirements engineering involves elicitation, analysis, specification, and validation of software requirements as well as the management of requirements during the whole life cycle of the software product [Bourque and Fairley 2014]. The software requirements are commonly classified in two groups. First, functional requirements are related to the functions that should be performed by the system [Bourque and Fairley 2014]. Secondly, the nonfunctional requirements are related to constraints or quality requirements [Bourque and Fairley 2014].

From the set of requirements elicited, we can design the software architecture. Software architecture corresponds to the structure or structures of the system, involving software components, the externally visible properties of those components, and the relationships among them [Bass et al. 2003]. In the process of architectural design, there are some decisions over the solutions to be applied, such as the architectural styles and the views that will be described and represented by architecture. Architectural Styles refer to a specialization of element and relation types, together with a set of constraints on how they can be used [Horowitz et al. 2007]. In software architecture, a view is a representation of the system from the perspective of a particular viewpoint [ISO 2011].

Related Work. First, two search strings were defined seeking to reduce bias in this activity. The search started on May 24, 2021 with the strings application on Google Scholar digital base. As a result, five studies [Mumbelli et al. 2020], [Lashari et al. 2018], [Raj and Jayanthi 2018], [Debauche et al. 2020] and [Manshor et al. 2019] were retrieved. Another similar paper found was [Feijó et al. 2021], which describes a decision support system for agribusiness. This support takes place through the indication of technical documents about environmental legislation with more sustainable environmental practices. The results gave us a better idea about the existing gaps in the area. It was possible to notice that part of the studies so far developed are not concerned about software engineering solutions, and thus, we did not find specifications about requirements elicitation process and just a few reports about architectural solutions.

A recent systematic mapping showed that there are some studies on monitoring aviaries. The study [Mumbelli et al. 2020] reports the elaboration of a low-cost prototype of a Poultry House Monitoring System. [Raj and Jayanthi 2018] provides some interesting results regarding the monitoring activity of poultry diseases. The study [Debauche et al. 2020] proposes an IoT-Based aviary monitoring system; however, the focus is on an artificial intelligence algorithm to predict environment parameters, not monitoring and operationalizing actions on the environment, as we propose.

In face of all the studies presented, our study conducted differently from all 
these related studies. One of our differentials is that our architectural design supports decision-making automation, which our requirements elicitation process showed to be a relevant function for farmers' monitoring work. That automation process seeks to reduce the need for a human being to control the temperature and ventilation of the aviary, in addition to speeding up the reaction time to correct an error in the environment, which can decrease the stress of the poultry and increase production. Another differential of our proposal are the adoption of a architectural design process [Hofmeister et al. 2007] and model [Kruchten 1995], which allowed us to design and define five different views of the system, a relevant document to critical systems since it must have a high level of quality to avoid failures and future losses.

Thus, we can also state that these studies are not concerned with elaborating a specific architecture for aviary monitoring that can serve as a basis for future works. The software solutions are not the main concern of them, as they are focused on how the system works as a hardware, or algorithms. Of course, some studies described some software architecture, such as [Raj and Jayanthi 2018] and [Lashari et al. 2018], but with few details, just describing system data flows. The contribution of our proposal is an architecture that can serve as a reference for a monitoring system with automated decision-making support, since the results obtained show an architecture that is concerned with the quality that this type of system must have. Besides that, this study presents requirements closer to the real needs of farmers than the previously mentioned studies, since this paper presents an interview process that supported the requirements elicitation with real farmers.

\section{Methodology}

In order to achieve the general goal of this study, research questions (RQ) were defined in Table 1.

Table 1. Research questions.

\begin{tabular}{|l|l|}
\hline ID & Description \\
\hline RQ01 & What monitoring difficulties do poultry producers face? \\
\hline RQ02 & $\begin{array}{l}\text { Is it possible to define an architecture to support the construction of monitor- } \\
\text { ing systems that solve one or more typical problems of poultry production? }\end{array}$ \\
\hline RQ03 & How does the proposed architecture meet the needs of poultry producers? \\
\hline
\end{tabular}

A methodology was defined to guide this study, which made possible to answer the research questions previously defined. The methodology's phases for software engineering's studies proposed by Neto, Spínola and Travassos [Dias-Neto et al. 2010] was used as a guideline. It can be seen in Figure 1.

Literature review: An informal literature review was performed seeking to provide an overview of the context under study and investigate gaps in the area. Part of the results are shown in Related work. Even though the literature review was not systematic, the reading process was based on the studies [Lopes et al. 2020], [Batista et al. 2021] and [Santos et al. 2021]. The second step refers to Requirements elicitation. This process was performed aiming to understand the real needs for the project. First, we have defined a requirements elicitation process based on an interviews. Thus, the interviews were 


\section{Conception Construction}

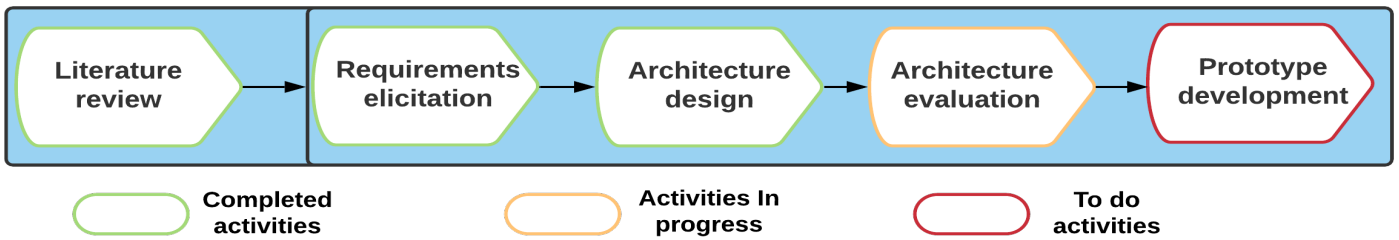

Figure 1. Scientific methodology proposed by Neto, Spínola and Travassos [Dias-Neto et al. 2010].

performed with real farmers, which enabled us to understand the rural worker needs and elaborate a requirements document. The requirements elicitation helped to answer RQ01.

Architecture design: An architecture was planned and specified. At the end of this activity an architectural document was elaborated. This document can be used to assist in the development and study of future work, since it is a new solution for the problems faced in this context. Architecture evaluation: An activity that is still in progress. The process consists of (i) a research in existing architectures in the context of critical systems, precision agriculture and precision livestock and (ii) the comparison of the architectures found with the one developed in this study. Prototype development: It refers to the instantiation of the conceived architecture in a proof-of-concept artifact. The software will be used for monitoring, gathering data and generate results on the benefits of IoT-Based applications in this area of study.

\section{Preliminary Results}

This section answers the research questions presented in Section 3. The RQ01 is answered by the Requirements elicitation process that is presented in this section. The RQ02 and RQ03 are answered by the architectural design also presented in this section.

\subsection{Requirements elicitation process}

The process was applied in an interview model. Three rural workers were interviewed. The answers were recorded and documented. The requirements document provided by this process is composed by three tables. The functional requirements table contains twenty-two requirements, the nonfunctional requirements table contains six items and a third table that refers to the business rules of the project is composed of eleven items. We chose to present and exemplify two tables that better represent the requirements document. The Table 2 represents the functional requirements and Table 3 exemplify the nonfunctional requirements. These two requirements of each table were chosen to represent the automation of the system and also the prevention of failures and interferences, which is an important part of our solution.

\subsection{Architectural design}

Our second activity is the architectural design. This activity is necessary because the solutions found so far in the literature [Mumbelli et al. 2020], [Debauche et al. 2020], 
Table 2. Table of functional requirements

\begin{tabular}{|l|l|l|}
\hline Functional requirements & Description & Priority \\
\hline $\begin{array}{l}\text { RF01 - Automatically } \\
\text { turn on the lamp }\end{array}$ & $\begin{array}{l}\text { The system should turn on the lamp(s) auto- } \\
\text { matically based on temperature parameters. }\end{array}$ & High \\
\hline $\begin{array}{l}\text { RF02 - Send failure notifi- } \\
\text { cation }\end{array}$ & $\begin{array}{l}\text { The system must send some notification or } \\
\text { warning to system users if it fails to receive } \\
\text { information from its sensors. }\end{array}$ & High \\
\hline
\end{tabular}

Table 3. Table of nonfunctional requirements

\begin{tabular}{|l|l|l|}
\hline Nonfunctional requirements & Description & Priority \\
\hline RNF01 - Availability & $\begin{array}{l}\text { The system must monitor the aviary 24 } \\
\text { hours a day. }\end{array}$ & High \\
\hline RNF02 - Reliability & $\begin{array}{l}\text { The system must not be interfered with by } \\
\text { any other device, sensor or actuator that is } \\
\text { not present in the system. }\end{array}$ & High \\
\hline
\end{tabular}

[Raj and Jayanthi 2018] do not support some essential features for this type of monitoring, such as the automation of decision making and failure prevention, which can avoid possible production losses, Figure 2 exemplifies these differences. Therefore, it is necessary to propose something new, thus, an architectural design process was conducted in conformance with the one prescribed by Hofmeister [Hofmeister et al. 2007], which defines activities to guide the architectural design process. The diagrams were produced in conformance to those defined in 4+1 view model proposed by Kruchten [Kruchten 1995]. The 4+1 view model [Kruchten 1995] defines five different views that were defined in our architecture document, the scenario view, the logical view, the developer view, the process view and the physical view.

\begin{tabular}{|c|c|c|c|}
\hline \multicolumn{2}{|c|}{ Architectures found in the literature } & \multicolumn{2}{|c|}{ Architecture proposed by this study } \\
\hline $\begin{array}{l}\text { Provide modules for } \\
\text { environment monitoring } \\
\text { through sensors }\end{array}$ & $\begin{array}{l}\text { Provide modules for data } \\
\text { visualization through } \\
\text { internet devices }\end{array}$ & $\begin{array}{l}\text { Provide modules for } \\
\text { environment monitoring } \\
\text { through sensors }\end{array}$ & $\begin{array}{l}\text { Provide modules for data } \\
\text { visualization through } \\
\text { internet devices }\end{array}$ \\
\hline & & $\begin{array}{l}\text { Provide modules to automate } \\
\text { decision-making. }\end{array}$ & $\begin{array}{l}\text { Provide modules for } \\
\text { solutions to system } \\
\text { failures }\end{array}$ \\
\hline & & \multicolumn{2}{|c|}{$\begin{array}{l}\text { Provide modules to instantiate more than one aviary } \\
\text { (enables monitoring of chicks and chickens) }\end{array}$} \\
\hline
\end{tabular}

Figure 2. Deployment diagram

First, Figure 3 is a representation of the overall architecture view. The monitoring device is responsible for monitoring and gathering data of luminosity, temperature, air 
humidity and device battery. This device is composed by a JARM ESP32 board, a SHT20 temperature and humidity sensor, a LoRa module, a SD card to store data from sensors, a DC plug that makes the device run directly on energy and a battery holder so that the device can still work in case of power failure. The gateway is also composed by a JARM ESP32, a LoRa module, a DC plug, a battery holder and a WIFI antenna to communicate with the ThingSpeak cloud and the platform through HTTP requests. There was a need for a LoRa/WiFi gateway to solve the problem of low WiFi connections in farms, thus enabling the sensor to communicate with the gateway at greater distances, where there is a better WiFi connection. This architectural design was made for each module to work individually. For example, the monitoring process is done only at the monitoring device part. All of the automation algorithms are located in a firmware on the ESP32 board, and all date gathered are stored in a SD card in the same device. Thus, if any failures happen on the gateway or on the platform, it would not affect the monitoring process.

Second, Figure 4 is a component diagram. The diagram describes the software components, their interfaces and their dependencies. In the diagram, there are thirteen components and three subsystems. The component called SensorNode, which is composed of sensors and actuators, communicates with the subsystem called DataControl. The DataControl subsystem is responsible for maintaining and processing data coming from the sensors, in addition to allowing the export of this type of data. DataControl communicates with the Accounting subsystem, which is responsible for maintain data regarding system user's accounts, in which each aviary is managed by an account. Accounting communicates with the WebDataView subsystem, which performing actions in the system, such as viewing sensor data and performing the user authentication process provided by the DataView and Authentication components respectively. Finally, the ClientBrowser component represents the user's current application.

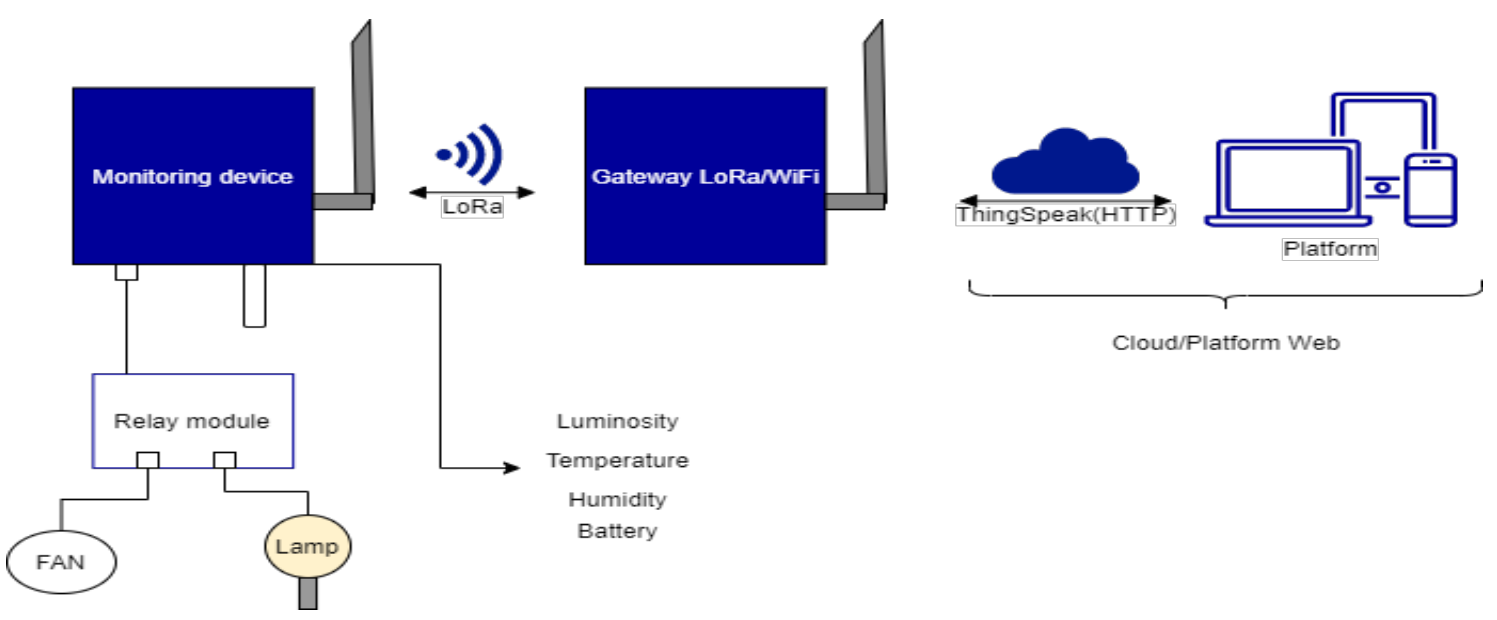

Figure 3. Overall Architecture

\section{Final Remarks}

This paper presented preliminary results of a study conducted on precision livestock farming envisioning the use of IoT-Based for automated decision in aviary monitoring systems. The main contributions so far are (i) results of an informal literature review, (ii) a proposal of a requirements elicitation process that can be successfully used with farmers and the 


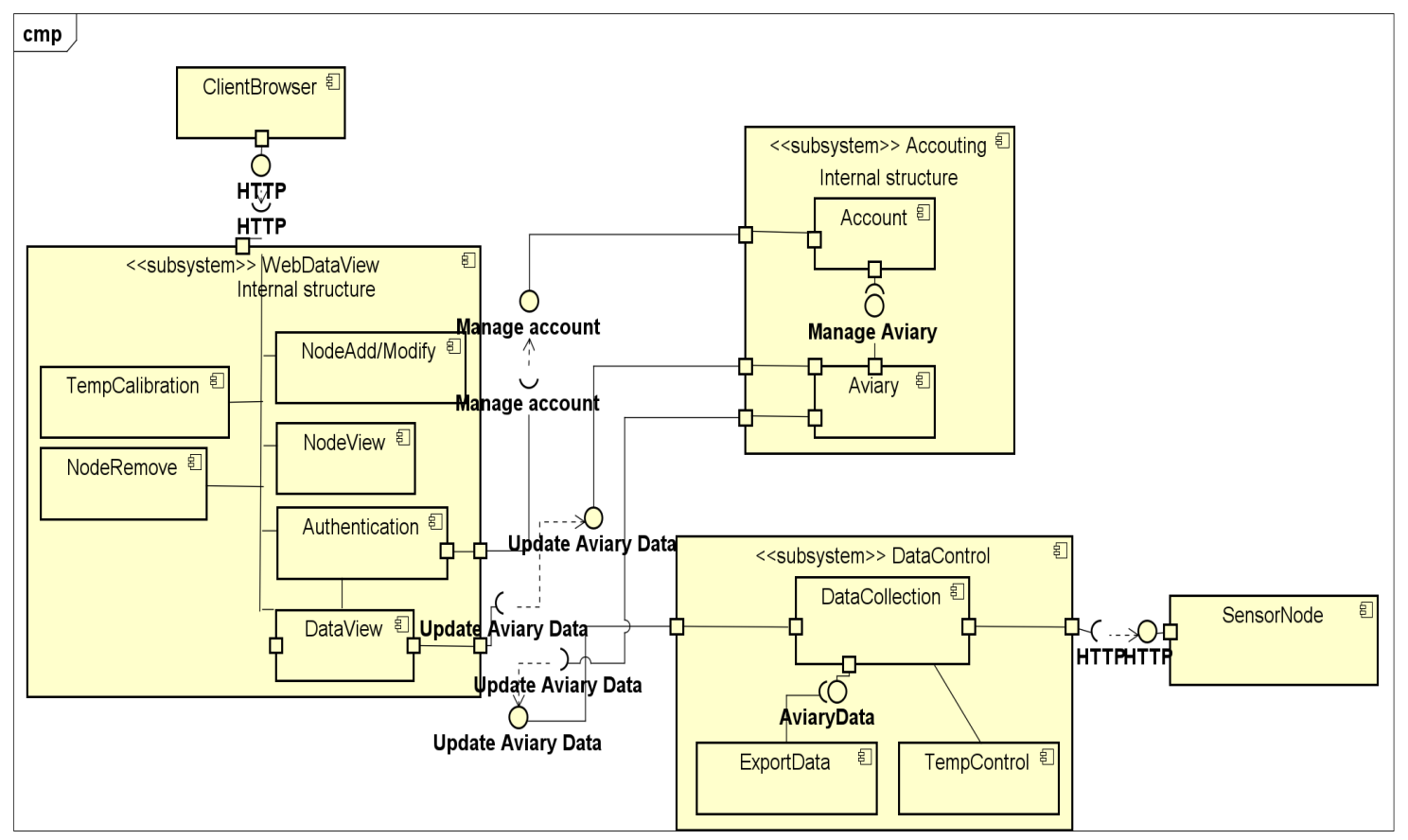

Figure 4. Component diagram

requirements themselves and (iii) an architectural design adapted to this context to satisfy the requirements elicited and to meet the automate and support decision-making main requirement. Based on our findings, we externalized them into a requirement document, which is composed of functional and non-functional requirements and an architecture document, composed by five diagrams. We are now finalizing the process of refining our architectural design. At the end, a prototype will be developed, deployed and evaluated.

\section{References}

(2011). ISO/IEC/IEEE Systems and software engineering. ISO/IEC/IEEE 42010:2011(E) (Revision of ISO/IEC 42010:2007 and IEEE Std 1471-2000), pages 1-46.

Bass, L., Clements, P., and Kazman, R. (2003). Software Architecture In Practice.

Batista, P. E. P., Bulcão Neto, R. d. F., Paes, C. E. d. B., Lima, E. A. d., Rohling, A. J., and Graciano Neto, V. V. (2021). Reference architecture for systems of systems: a systematic mapping. iSys - Brazilian Journal of Information Systems, 14(1):119-153.

Berckmans, D. (2006). Automatic on-line monitoring of animals by precision livestock farming. Livestock production and society, 287:27-30.

Bourque, P. and Fairley, R. E., editors (2014). SWEBOK: Guide to the Software Engineering Body of Knowledge. IEEE Computer Society, Los Alamitos, CA, version 3.0 edition.

Camargo, T. F., Silva, R. L., Higa, M., Coutinho, M. R., de Oliveira, J. C., and Conceição, W. A. d. S. (2019). Monitoramento do conforto térmico em aviários mediante sistemas de aquisição de dados em tempo real. Revista Brasileira de Engenharia Agrícola e Ambiental, 23(9):694-701. 
Choukidar, G. A. and Dawande, N. (2017). Smart poultry farm automation and monitoring system. In 2017 ICCUBEA, pages 1-5. IEEE.

da Silva Oliveira, G., dos Santos, V. M., Rodrigues, J. C., and Nascimento, S. T. (2019). Protótipo para o estudo do comportamento e da zona de conforto térmico de frangos de corte. REVISTA EIXO, 8(1).

Debauche, O., Mahmoudi, S., Mahmoudi, S. A., Manneback, P., Bindelle, J., and Lebeau, F. (2020). Edge computing and artificial intelligence for real-time poultry monitoring. Procedia Computer Science, 175:534-541.

Dias-Neto, A. C., Spinola, R., and Travassos, G. H. (2010). Developing software technologies through experimentation: experiences from the battlefield. In XIII CIbSE.

Feijó, T., David, J. M., Braga, R., Otenio, M. H., Paula, V. R., Santos, G. M., Campos, F., and Stroele, V. (2021). @ grogestambiental: A web-based decision support system for agribusiness. WebMedia '21, page 1-8, New York, NY, USA. Association for Computing Machinery.

Hofmeister, C., Kruchten, P., Nord, R. L., Obbink, H., Ran, A., and America, P. (2007). A general model of software architecture design derived from five industrial approaches. Journal of Systems and Software, 80(1):106-126.

Horowitz, E., Sahni, S., and Rajasekaran, S. (2007). Computer Algorithms. Silicon Press, USA, 2nd edition.

Kruchten, P. B. (1995). The 4+ 1 view model of architecture. IEEE software, 12(6):42-50.

Lashari, M. H., Memon, A. A., Shah, S. A. A., Nenwani, K., and Shafqat, F. (2018). Iot based poultry environment monitoring system. In 2018 IEEE IOTAIS, pages 1-5.

Lopes, V. C., Norberto, M., R. S., D. W., Kassab, M., da Silva Soares, A., Oliveira, R., and Neto, V. V. G. (2020). A systematic mapping study on software testing for systemsof-systems. SAST 20, page 88-97, New York, NY, USA. Association for Computing Machinery.

Manshor, N., Rahiman, A. R. A., and Yazed, M. K. (2019). Iot based poultry house monitoring. In 2019 2nd ICCET, pages 72-75. IEEE.

Mumbelli, A., Brito, R. C., Pegorini, V., and Priester, L. F. (2020). Low cost iot-based system for monitoring and remote controlling aviaries. In $20203 \mathrm{rd}$ ICICT, pages 531535. IEEE.

Pessoa, G. T., de Sousa, G. V., Ferraz, M. S., Feitosa, M. L. T., and de Miranda Sampaio, A. (2013). Estratégias inovadoras no manejo de frangos de corte em avicultura industrial: fases pré-inicial, inicial, engorda e final. Pubvet, 7:1002-1136.

Raj, A. A. G. and Jayanthi, J. G. (2018). Iot-based real-time poultry monitoring and health status identification. In 2018 11th ISMA, pages 1-7.

Santos, D., Basso, F., Luizelli, M., and Cabrera, S. (2021). Emprego de simulações computacionais em problemas envolvendo agricultura: Um estudo de mapeamento sistemático. In Anais do III Workshop em Modelagem e Simulação de Sistemas Intensivos em Software, pages 20-29, Porto Alegre, RS, Brasil. SBC. 